\title{
IN VITRO AND IN VIVO ANTIANGIOGENIC EFFECT OF ARTOCARPUS HETEROPHYLLUS SEED EXTRACT
}

\author{
THIRUSELVI M ${ }^{1}$, BRINDHA DURAIRAJ ${ }^{2 *}$
}

${ }^{1}$ Department of Biochemistry, Dr. NGP Arts and Science College, Coimbatore, Tamil Nadu, India. ${ }^{2}$ Department of Biochemistry, PSG College of Arts and Science, Coimbatore, Tamil Nadu. India. Email: brindhavenkatesh6@gmail.com

Received: 23 April 2018, Revised and Accepted: 26 May 2018

\section{ABSTRACT}

Objective: Angiogenesis the formation of new blood vessels from the pre-existing vasculature plays a major role in tumor growth, invasion, and metastasis of cancer diseases. The current research was designed for the inhibition of angiogenesis, which can provide a novel way to inhibit tumor growth and metastasis in cancer.

Methods: The antiangiogenic properties of serial concentrations of the hydroethanolic extract of Artocarpus heterophyllus were examined in human umbilical vein endothelial cells (HUVECs) using a tube formation assay in vitro and in a Matrigel plug assay as in vivo model.

Results: Hydroethanolic extract of $A$. heterophyllus significantly inhibited vascular endothelial growth factor (VEGF)-mediated angiogenesis in the HUVECs in culture dose-dependently. Further, the new blood vessel formation was observed to be inhibited by the extract at $100 \mathrm{mg} / \mathrm{kg}$ p.o. in Matrigel plug model in C57BL/6 mice. However, the effect was enhanced in higher concentration (500 mg/kg p.o.) demonstrating the in vivo antiangiogenic activity of the extract.

Conclusion: This study demonstrated that the hydroethanolic seed extract of $A$. heterophyllus strongly inhibited the angiogenesis in HUVECs. Moreover, the extract significantly inhibited the VEGF production in HUVECs, confirming their possible antiangiogenic mechanism.

Keywords: Angiogenesis, Vascular endothelial growth factor, Human umbilical vein endothelial cells.

(C) 2018 The Authors. Published by Innovare Academic Sciences Pvt Ltd. This is an open access article under the CC BY license (http://creativecommons. org/licenses/by/4. 0/) DOI: http://dx.doi.org/10.22159/ajpcr.2018.v11i9.27488

\section{INTRODUCTION}

Angiogenesis is the development of new blood vessels from preexisting blood vessels. It is host-dependent and is a hallmark of cancer that has an early permissive role in tumorigenesis [1]. The process of neovascularization not only allows the continued growth of the primary tumor but also provides migrating tumor cell access to the systemic circulation thereby facilitating metastasis [2]. In recent years, the involvement of angiogenesis in the development of malignant tumors and metastasis has been extensively studied. Therapeutic strategies to suppress angiogenesis have been examined on experimental tumor models with successful outcomes. Most cancer chemopreventive drugs, function by preventing angiogenesis in the tumor microenvironment by blocking vascularization [3]. Molecules possessing antiangiogenic effect hold great potential for treating diseases. During normal physiological conditions, the balance between angiogenic and antiangiogenic factors is essential for regulating angiogenesis [4]. Vascular endothelial growth factor (VEGF) and its tyrosine kinase VEGF receptors (VEGFRs) are the key regulators in angiogenesis and are highly conserved across vertebrate species [5]. Among them, VEGF-A, the most important member of the VEGF family, binds and activates the VEGFR2, and subsequently, activates the main signaling pathway [6]. This process of analyzing angiogenesis is studied using both in vitro and in vivo models using endothelial cell lines derived from human umbilical cord vein, or organ-specific endothelial cells have been used [7].

Medicinal plants represent a vast potential source for anticancer compounds by preventing angiogenesis. These plant-derived bioactive compounds for anticipation, mitigation, and therapeutics for cancer have been applied extensively which are otherwise extremely complex molecular structures, which would be difficult to synthesize (or conceptualize) in the laboratory. The antitumor activity of medicinal plant-derived compounds may result through a number of mechanisms, including effects on cytoskeletal proteins which play a key role in cell division, inhibition of DNA topoisomerase enzymes, antiprotease or antioxidant activity, and stimulation of the immune system. [8]. The natural compounds isolated from medicinal plants or parts of plants consumed in the form of food are believed to be major leads in the designing of anticancer medications. Screening of such medicinal plants and their bioactive constituents for several biological activities, such as anticancer activity, has been a key research area since last few decades [9]. Among which, many parts of plants have also provoked potential antiangiogenic activity. One such plant is Artocarpus heterophyllus which has been proved for its antioxidant and anticancer studies and not proved for its antiangiogenic property, so the current research focused on antiangiogenic property of the seed extract.

A. heterophyllus Lam, the plant used in the present investigation (Family; Moraceae) is of great interest, which is commonly known as jackfruit and is widely distributed in the tropical and temperate regions of the world. Secondary metabolites, including alkaloids, saponins, flavonoids, and phenolic content, were determined in the jackfruit seeds. The seeds are also a rich source of carbohydrates and proteins and a good source of fiber and vitamins [10]. The jackfruit seeds are consumed, usually as roasted, boiled, or steamed as a snack. Based on the minimum reports available, the present study is aimed to assess the antiangiogenic potential of the hydroethanolic extract of tegmen of A. heterophyllus seeds.

\section{METHODS}

Plant materials and extraction

A. heterophyllus seeds were obtained from Market, Trivandrum, Kerala. The inner thin membranous brown tegmen (Spermoderm) of A. heterophyllus seeds was used for the present study. The plant was identified and authenticated at Botanical Survey of India, Coimbatore 
(No: BSI/SRC/5/23/2018/Tech-383). About $25 \mathrm{~g}$ of the inner thin membranous brown tegmen of the jackfruit seed was dried and powdered. The powdered material of A. heterophyllus seeds was extracted with hydro-ethanol using Soxhlet extractor exhaustively for 20-24 h. The extracts were concentrated to dryness under reduced pressure and controlled temperature $\left(40-50^{\circ} \mathrm{C}\right)$. The dried extracts obtained were used in this study.

\section{Tube formation assay}

Matrigel $^{\text {'"' }}$ (BD Biosciences, Heidelberg, Germany) was thawed at $4^{\circ} \mathrm{C}$ overnight. 96-well plate was coated with 50- $\mu$ l Matrigel'" per well and incubated at $37^{\circ} \mathrm{C}$ for $20 \mathrm{~min}$ for polymerization. Human umbilical vein endothelial cells (HUVECs) $\left(2 \times 10^{5}\right.$ cells $/ \mathrm{ml}$ of endothelial growth medium) were seeded onto the Matrigel $\mathrm{l}^{\mathrm{m}}$ coated plate and treated with different concentration of extracts. After $18 \mathrm{~h}$ incubation, the endothelial tube-like structure, which was defined as endothelial tube formations that connected at both ends, is observed under the microscope (Leica DM IRB microscope) and scored [11].

\section{Animal maintenance}

All animals taken for the study were handled similarly and with due regard for their welfare. Care of animals complied with the regulations of Committee for the Purpose of Control and Supervision of Experiments on Animals, Government of India. The study design was reviewed and approved by the Institutional Animal Ethics Committee (protocol number-07/IAEC-01/CAN/2015). 68-week-old C57BL/6 mice were taken from an in-house breeding facility of Orchid Chemicals and Pharmaceuticals Ltd., Chennai, India. Animals were maintained in individually ventilated cages, Allentown systems with a controlled environment, a temperature of $22 \pm 3^{\circ} \mathrm{C}$, humidity of $50 \pm 20 \%$, a light/ dark cycle of $\sim 12 \mathrm{~h}$, and minimum 50 fresh air changes per hour.

\section{In vivo matrigel plug assay}

Matrige $^{\mathrm{TM}}$ the gelatinous protein mixture was thawed on ice overnight at $4^{\circ} \mathrm{C}$. Aliquots of $0.5 \mathrm{ml}$ of Matrige ${ }^{\mathrm{TM}}$ (containing VEGF 165 and heparin) [11] were injected subcutaneously into the sides of each mouse. 68-week-old male C57BL/6 mice were taken from in-house breeding. The dose of an individual animal was adjusted based on the body weight. All visible clinical signs were observed once a day throughout the experimental period. All the animals were checked daily for morbidity, mortality, and body weight. At the end of the study, animals were euthanized by $\mathrm{CO}_{2}$ to excise the Matrigel plugs from the animals. Matrigel plugs from the control and treatment groups were photographed and then fixed in $10 \%$ formalin $<24 \mathrm{~h}$, and histopathology studies were carried out.

\section{Histopathology}

Matrigel plugs were fixed at $10 \%$ buffered formalin and processed in automatic tissue processor (Citadel 2000, Thermo Shandon, UK) embedded with the help of automatic tissue embedded (Histocenter2, Thermo Shandon, USA) in paraffin. $3-5-\mu$ sections were taken using microtome (Finesse-E, Thermo Shandon, UK) in positively charged frosted slides for Hematoxylin (Himedia, 51694) and Eosin (Himedia, 81692) staining. The sections were examined using a light microscope (NIKON, ECLIPSE-E200, Japan). Scoring for the Matrigel sections for the microvessels is quantified based on Kwon et al. [10]. The submitted pretrimmed Matrigel plugs were routinely processed using alcohol, xylene, and embedded in paraffin wax. Apart from that, the plug sections were scored using Nikon eclipse 200 microscopes fitted with a calibrated 1 -mm reticle in the eyepiece. Based on the reticle length of $2.5 \mu$ per division in $\times 400$ magnification, the area of the same magnified field was calculated to be $\sim 1.57 \mathrm{~mm}^{2}$ by the formula pi Xd where $\mathrm{d}=0.4995 \mu$. Several $\times 400$ magnified fields were examined covering the entire plug section without allowing the fields to overlap and assess the area of entire plug section in $\mathrm{mm}^{2}$.

\section{Statistical analysis}

The values are expressed as mean \pm standard error of the mean. The graphs were generated using GraphPad Prism ${ }^{\circledR}$ (Version 4). Statistical analysis was performed by two-way ANOVA followed by Bonferroni post-test and one-way ANOVA followed by Dunnett's post-test.

\section{RESULTS}

\section{Tube formation assay}

Hydroethanolic extract of $A$. heterophyllus prevented VEGFstimulated tube formation of HUVECs, in a dose-dependent manner $(50 \mu \mathrm{g} / \mathrm{kg}-200 \mu \mathrm{g} / \mathrm{kg} ;$ Fig. 1 : AD). The extract at different doses exhibited the inhibition of tube formation of HUVECs. The VEGFdependent angiogenesis was found to be inhibited by the extract dosedependently. The complete inhibition of tube formation was observed at higher concentrations where most of the cells appeared as unorganized cell aggregates.

Tube formation assay in HUVECs was seeded onto the Matrigel ${ }^{\mathrm{TM}}$-coated plate; the cells were treated for $18 \mathrm{~h}$ with hydroethanolic extract; their endothelial tube-like structure images was captured; and an apoptotic score of various concentration of extract is as shown in Table 1.

\section{An antiangiogenic activity of a hydroethanolic extract of A. heterophyllus}

The in vitro antiangiogenic property of a hydroethanolic extract of $A$. heterophyllus was further studied in vivo in the Matrigel ${ }^{\text {t" }}$ plug angiogenesis assay. The effect on neovascularization in responses to VEGF-A was evaluated by injecting Matrigel ${ }^{\text {"' }}$ (with and without
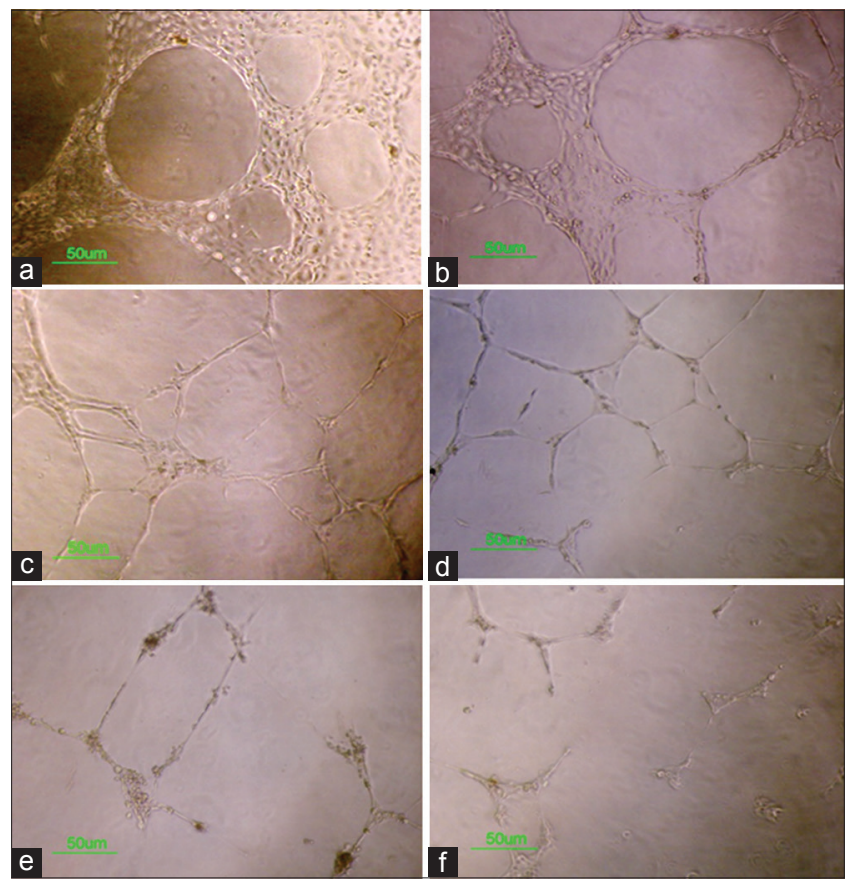

Fig. 1: The effect of Artocarpus heterophyllus in tube formation assay in human umbilical vein endothelial cells. (a) control, (b) extract $50 \mu \mathrm{g}$, (c) extract $100 \mu \mathrm{g}$, (d) extract $150 \mu \mathrm{g}$, (e) extract $200 \mu \mathrm{g}$, and (f) curcumin $10 \mu \mathrm{M}$

Table 1: Matrigel scoring system

\begin{tabular}{lll}
\hline Compound & Concentration $(\boldsymbol{\mu m} / \boldsymbol{\mu g})$ & Score \\
\hline Control & - & 4 \\
Curcumin & 10 & 1 \\
Hydroethanolic extracts & 50 & 4 \\
& 100 & 3 \\
& 150 & 2 \\
& 200 & 1 \\
\hline
\end{tabular}

Apoptotic score for hydroethanolic extract at various concentration;

curcumin-internal standard; control-untreated control 
supplements of VEGF-A and Heparin) subcutaneously into the flank regions of C57/BL6 mice. Animals were treated with different concentrations of the hydroethanolic extract of A. heterophyllus for 10 days. The onset of neovascularization within the Matrigel" plug was evaluated by histology. The Matrigel'" plugs in the control group - VEGF-A added groups were visually bloodier which suggests an enhanced level of angiogenesis (Fig. 2). Hematoxylin and Eosin staining of the vasculature within the plugs has revealed more vessellike structures within the vehicle control VEGF-A supplemented group than the treated. Although the blood vessel formation was not significantly inhibited at lower doses, however, at higher concentrations, the blood vessel formation was significantly inhibited $(\mathrm{p}<0.01)$, demonstrating the in vivo antiangiogenic activity of the hydroethanolic extract in the Matrigel" plug angiogenesis assay (Fig. 3 ). There was observed $>50 \%$ inhibition of blood vessels in mice treated with higher concentration $(500 \mathrm{mg} / \mathrm{kg} \mathrm{p.o)}$ of hydroethanolic extract compared with controls, suggesting the demonstrating the in vivo antiangiogenic activity of the hydroethanolic extract. Fig. 4

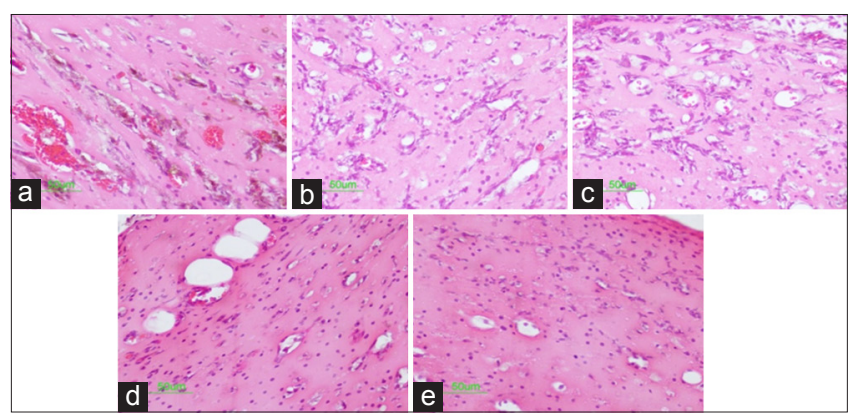

Fig. 2: Histological representative slides of Matrigel pluginhibition of tube formation. (a) Vehicle control vascular endothelial growth factor, (b) extract $100 \mathrm{mg} / \mathrm{kg}$ p.o, (c) extract $250 \mathrm{mg} / \mathrm{kg}$ p.o, (d) extract $500 \mathrm{mg} / \mathrm{kg} \mathrm{p.o,} \mathrm{and} \mathrm{(e)} \mathrm{curcumin}$ $100 \mathrm{mg} / \mathrm{kg} \mathrm{p.o}$

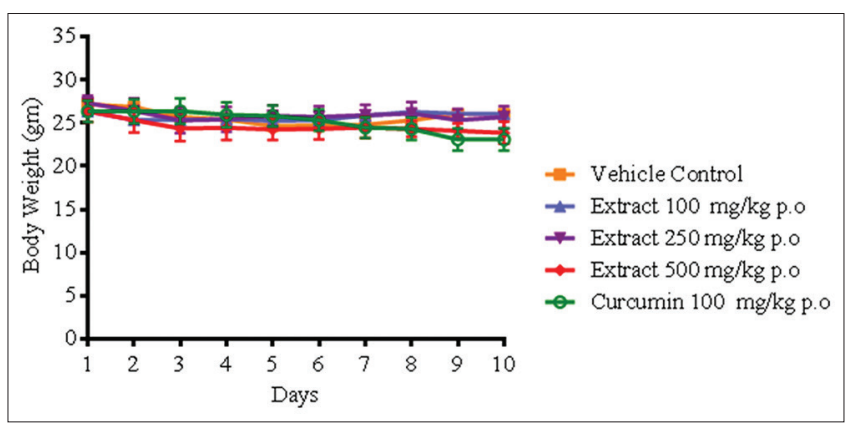

Fig. 3: The effect of the hydroethanolic extract of Artocarpus heterophyllus inhibited the new blood vessel formation describes the photographed images of Matrigel plug after treatment of extract at different concentrations.

\section{DISCUSSION}

Cancer is a molecularly heterogeneous disease and the leading cause of death worldwide [12]. Despite many advance research has focused on cancer prevention, considerable attention has focused on medicinal plants as a major source of anticancer agents for a long time in the history of oncology treatment. There are more attempts being made to study the role of seeds, spices, and plant parts and their constituents in therapeutic and pharmacological applications, such source derived phytochemicals have an enormous potential in the prevention and treatment of cancer. They can induce apoptosis, suppress proliferation of tumor cells, and inhibit invasion and angiogenesis

$[13,14]$. The new pharmacological effects of $A$. heterophyllus have been confirmed by the proven inhibition of angiogenesis both in vitro and in vivo studies. In the present study, the evaluation of the arrest of endothelial cells and angiogenesis by blocking the VEGF signaling pathway. We further demonstrated the antiangiogenic potential of hydroethanolic extract of $A$. heterophyllus inhibitors on various angiogenic functions of HUVECs, the most commonly used endothelial cell for in vitro angiogenesis assays. Boerhaavia diffusa extracts support strong claims of antiangiogenic ethnomedical properties by chicken chorioallantoic membrane (CAM) assay in vivo [15] The chick CAM treated with methanolic leaf extract and methanolic flower extracts of Calotropis procera showed distorted vascularization revealing potent antiangiogenic property [16]. The process of angiogenesis depends on the increase in the viability and proliferation of endothelial cells, and VEGF is a major pro-angiogenic factor that governs angiogenesis, in both physiological and pathological settings. Secretion of VEGF by tumor cells in response to hypoxia is an important factor that drives tumor angiogenesis [17]. Extract of Vigna angularis effectively attenuated the phosphorylation ofVEGFR2,Erk, and Akt in VEGF-treated HUVECs [18] To confirm in vivo antiangiogenic activity of hydroethanolic extract, Matrigel plug assay was performed in mice orally administered by extracts. Angiogenesis is processed through the interaction of the VEGF family of pro-angiogenic cytokines and their receptors. The VEGF family includes VEGF-A, VEGF-B, VEGF-C, VEGF-D, VEGF-E, and placental growth factor with three receptors including VEGFR-1 (fms-like tyrosine kinase 1/Flt- 1), VEGFR-2 (flk-1/KDR), and VEGFR-3 $[19,20]$. The ethanolic extract of Artemisia sieberi is strongly inhibited the angiogenesis in HUVECs and chick CAM models, by reducing the transcription of VEGFR-1, VEGFR-2, and CD34 genes in a concentration-dependent manner [21]. From the current study, we report that $A$. heterophyllus significantly suppressed the VEGF-induced angiogenesis. Such food-based therapeutic approach may be safer to use, and more number of animal studies and clinical trials are needed to prove the usefulness of these agents.

\section{CONCLUSION}

Our current research emphasized on the use of the hydroethanolic extract of $A$. heterophyllus for its antiangiogenic potential through direct inhibition of endothelial cell as well as it was found to possess in vivo angiogenesis with less toxicity to mice. The angiogenic potential

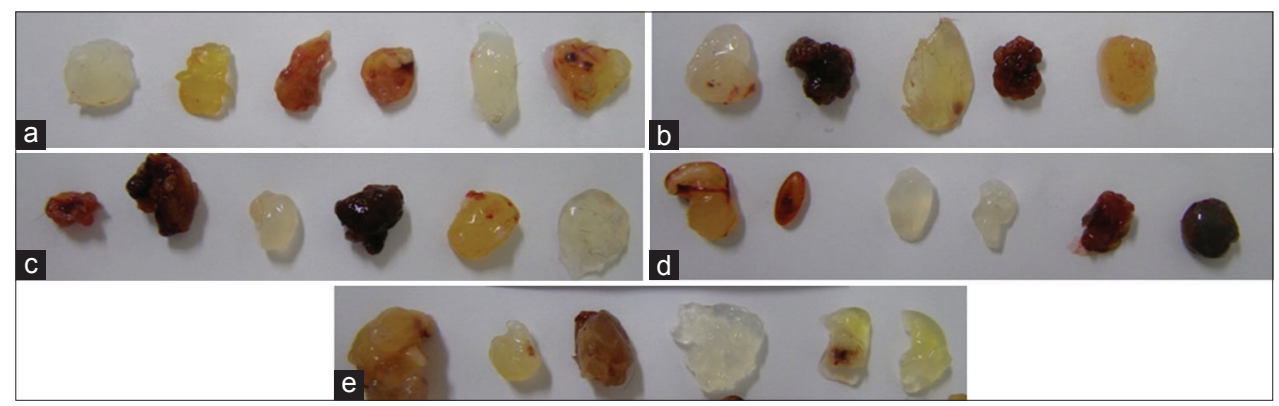

Fig. 4: The effect of Artocarpus heterophyllus in Matrigel at different concentration. (a) Vehicle control - matrigel+vascular endothelial growth factor, (b) extract $100 \mathrm{mg} / \mathrm{kg} \mathrm{p.o,} \mathrm{(c)} \mathrm{extract} 250 \mathrm{mg} / \mathrm{kg} \mathrm{p.o,} \mathrm{(d)} \mathrm{extract} 500 \mathrm{mg} / \mathrm{kg} \mathrm{p.o,} \mathrm{and} \mathrm{(e)} \mathrm{curcumin} 100 \mathrm{mg} / \mathrm{kg} \mathrm{p.o}$ 
of $A$. heterophyllus might have been executed either by preventing signaling of angiogenic agents from epithelial cells or by induction of apoptosis, preventing promotional events in the tissues. However, further studies are needed to elucidate the exact mechanism underlying the antiangiogenic property of $A$. heterophyllus. The profound results might generate better clinical understanding and generate new therapeutic approaches.

\section{REFERENCES}

1. Carmeliet P, Jain RK. Angiogenesis in cancer and other diseases. Nature 2000;407:249-57.

2. Cross MJ, Dixelius J, Matsumoto T, Claesson WL. VEGF-receptor signal transduction. Trends Biochem Sci 2003;28:488-94.

3. Deepika G, Sonia M, Avijit S, Gupta KR. Phytochemical, nutritional and antioxidant activity evaluation of seeds of jackfruit. Int J Pharm Bio Sci 2011;2:337-9.

4. Duarte M, Filho AL, Schmit FC. Angiogenesis, and cancer: New paradigms and old concerns. J Bras Patol Med Lab 2007;43:441-9.

5. Hanahan D, Weinberg RA. Hallmarks of cancer: The next generation. Cell 2011;144:646-74.

6. Holmes DI, Zachary I. The vascular endothelial growth factor (VEGF) family: Angiogenic factors in health and disease. Genome Biol 2005;6:209

7. Jadhav J, Mane A, Kanase A. Antiangiogenic properties of Boerhaavia diffusa extracts in chick chorioallantoic membrane (CAM). Int J Drug Dev Res 2011;3:307-17.

8. Kato Y, Yoshimura K, Shin T, Verheul H. Hammers H. Synergistic in vivo antitumor effect of the histone deacetylase inhibitor MS-275 in combination with interleukin 2 in a murine model of renal cell carcinoma. Clin Cancer Res 2007;13:4538-46.

9. Ravin S, Gourav CD, Anterpreet C, Reena VS. The antioxidant and anticancer activity of methanolic extract from Stephania elegans. Int J Pharm Pharm Sci 2017;9:245-9.

10. Kwon OS, Jeong MS, Kim B, Kim SH. Antiangiogenic effect of ethanol extract of Vigna angularis via inhibition of phosphorylation of VEGFR2. Evid Based Complement Altern Med 2015;2015:371368.

11. Saranya N, Thippeswamy BS, Chandrasekhar KB, Reddy ND, Kulkarni NM, Narayanan S, et al. Pharmacodynamics properties of histone deacetylase inhibitor MS-275 is enhanced in combination with phosphodiesterase inhibitor pentoxifylline in human breast cancer. Eur J Pharm 2015;764:508-19.

12. Jainab HN, Raja MK. In-vitro cytotoxic and apoptosis study of chemical constituents of Clerodendrum phlomidis leaf on mcf-7 breast and a-549 lung cancer cell lines. Asian J Pharm Clin Res 2018;11:209-304.

13. Mohan RN, Rajashekhar RN, Kaiser J. Spicy anti-cancer spices: A review. Int J Pharm Pharm Sci 2015;7:1-6.

14. Saka S, Singh AN, Sharma N. Potential anti-cancer superfoods: A mini review. Int J Curr Pharm Res 2016;8:19-21.

15. Sitohy B, Nagy JA, Dvorak HF. Anti-VEGF/VEGFR therapy for cancer: Reassessing the target. Cancer Res 2012;72:1909-14.

16. Kalimuthu K, Prabakaran R, Chinnadurai V. Antiangiogenic properties stem, leaf and flower extracts of Calotropis procera in chick chorioallantoic membrane (CAM). World J Pharm Pharm Sci 2014;3:777-84.

17. Staton CA, Reed MW, Brown NJ. A critical analysis of current in vitro and in vivo angiogenesis assays. Int J Exp Pathol 2009;9:195-221.

18. Tosetti F, Ferrari N, De Flora S, Albini A. Angio prevention: Angiogenesis is a common and key target for cancer chemo preventive agents. FASEB J 2002;16:2-14.

19. Wang N, Chen L, Zhang L, Jiang R, Chen L, Shen Y. Inhibitory effect of suberoylanilide hydroxamic acid on angiogenesis and its molecular mechanism. Chin J Cell Mol Immunol 2014;30:266-9.

20. Zohara YB. The contribution of selected medicinal plants for cancer prevention and therapy. Sci J Fac Med 2012;29:117-23.

21. Abdolmaleki Z, Araba H, Amanpour S, Muhammadnejad S. Antiangiogenic effects of ethanolic extract of Artemisia sieberi compared to its active substance, artemisinin. Braz J Pharm 2016;26:326-33. 